\title{
EDITORIAL
}

\section{Plaques, tangles and Alzheimer's disease ${ }^{1}$}

For the purpose of this review, Alzheimer's disease and senile dementia of Alzheimer type will be considered as the same disease process, a view broadly accepted at this time.

For total satisfaction in morphological diagnosis, both plaques and tangles need to be present in large or considerable numbers in the neocortex. In most pre-senile cases both are present in vast numbers: in many cases below the age of 80 years a similar picture exists but, in extreme old age, demented subjects may have many plaques but a few or no demonstrable tangles occur (Tomlinson et al. 1970; Terry, personal communication) and, occasionally, in the pre-senium or senium relatively few or no plaques may be found in the presence of large numbers of tangles (Corsellis, 1976a). Both these appearances have been accepted as variants of Alzheimer's disease, but perhaps some reservations about such a decision are necessary.

Since the original reports of Kidd (1963, 1964), Terry (1963), Terry et al. (1964) and Krigman et al. (1965), the ultrastructure of plaques and tangles has been largely agreed. Plaques which are visible on light microscopy, and vary from 15 to $200 \mu \mathrm{m}$ in diameter, are clusters of abnormal, enlarged nerve processes and terminals surrounding a central mass of amyloid fibrils, and associated with some astrocytic processes and microglia. The enlarged terminals (often termed neurites) are ballooned by lamellar lysosomes, abnormal mitochrondria and paired helical filaments (PHF) identical with those which form the neurofibrillary tangle. The smallest (earliest) plaque not visible on light microscopy is said to consist of three or four distended neurites with no evidence of amyloid fibrils, and the oldest is a mass of amyloid with few surrounding neurites remaining (Terry \& Wisniewski, 1970).

Gonatas et al. (1967) and Gonatas \& Gambetti (1970) considered the majority of neurites as pre-synaptic (or axonal) and emphasized the presence of changes which suggest regeneratıve actıvity. Terry \& Wisniewski (1970) identified apparently normal synapses on the neurites and regarded the post-synaptic element as largely normal; Ishii (1976), however, identified both abnormal pre- and post-synaptic terminals as well as abnormal synapses.

Tangles consist of large clusters (Kidd, 1963; Wisniewski et al. 1976a) of PHF each 10-13 nm wide, which measure around $22 \mathrm{~nm}$ at their widest and are reduced to approximately $10 \mathrm{~nm}$ at intervals of $80 \mathrm{~nm}$. In affected neurons bundles of PHF fill much of the cell soma, displacing and intermingling with otherwise apparently normal cytoplasmic elements. Although total agreement was reached on the interpretation of the fibrils as PHF rather than twisted tubules only after a number of years (Wisniewski et al. 1976a), reports were largely consistent that tangles were made up of such structures. Gibson et al. (1976), however, illustrated abnormally large numbers of straight tubules as well as the twisted variety. Mixtures of both straight and twisted filaments as well as tangles of both varieties have been reported by Yagashita et al. (1981); and Oyanagi (1979) also observed 15 $\mathrm{nm}$ straight filaments in some dendrites. Shibayama \& Kitoh (1978) have also observed both straight and paired helical filaments in a case of atypical senile dementia. The mixture of straight and helically wound filaments clearly needs bearing in mind in chemical and immunological studies of these structures. Perhaps the only other well established abnormality in the neuron affected by tangle formation is a diminution in the size of the nucleolus (Dayan \& Ball, 1973), though additionally, in the hippocampus only, tangles frequently occur along with granulovacuoles in the same cell, the latter being an additional neuronal alteration which occurs in higher concentration in Alzheimer's disease than in normal old subjects (Woodard, 1962, 1966; Tomlinson \& Kitchener, 1972).

\footnotetext{
${ }^{1}$ Address for correspondence: Professor B. E. Tomlinson, Department of Pathology, Newcastle General Hospital, Newcastle upon Tyne NE4 6BE.
} 
The ultrastructure of the tangles in Alzheimer's disease is not unique to that condition and normal old age. Identical tangles are found in large numbers in the cortex and deep grey matter in the Parkinsonism dementia complex of Guam (Malamud et al. 1961; Hirano et al. 1961 ; Hirano, 1974), in the anterior temporal cortex and substantia nigra in dementia pugilistica (Corsellis et al. 1973; Wisniewski et al. 1976 b), in the substantia nigra and locus coeruleus of post-encephalitic Parkinsonism (Wisniewski et al. 1970 a), in the cortex of occasional cases of subacute sclerosing pan-encephalitis (Manydbur et al. 1977; Paula-Barbosa et al. 1979), and extensively in the majority of cases of Down's syndrome surviving to middle life (Olson \& Shaw, 1969; Burger \& Vogel, 1973; Solitare \& Lamarche, 1966; Jervis, 1948). In the latter subjects, senile plaques are also present in large numbers and the appearances are indistinguishable histologically from Alzheimer's disease. Clearly, therefore, PHF develop in a variety of unrelated conditions as divergent as repeated cerebral trauma and virus infection; it need hardly be emphasized that three of the disorders mentioned above are of proven or suspected viral origin, and that a genetic factor is suggested by their occurrence in Down's syndrome. In sporadic motor neuron disease and progressive supranuclear palsy, the tangles differ from the above conditions in consisting predominantly of bundles of straight fibres and not PHF.

Tangles and plaques, though far more frequent in the cortex than elsewhere, occur in the deeper brain structures. Plaques outside the cortex are probably most numerous in the mamillary bodies, but do occur in the basal ganglia, hypothalamus, upper brain stem and cerebellum, the latter rarely. Tangles may be seen in small numbers in any deep nuclear mass, in the substantia nigra and locus coeruleus, but rarely in Alzheimer's disease or normal old age in the lower stem, cerebellum or spinal cord.

The variations in findings in demented old subjects, plus the the well-known occurrence of neocortical plaques and hippocampal tangles in the majority of old people who are not demented, raise many questions about the relationship of plaques and tangles with each other, their formation and relationship with the dementing process and old age, and the relationship of old age and Alzheimer's disease.

Plaques and tangles are common in old age in intellectually well-preserved old subjects, but with major differences in the numbers of plaques and the numbers and distribution of tangles, compared with demented subjects (Tomlinson, 1972, 1977; Tomlinson et al. 1968, 1970; Matsuyama \& Nakamura, 1978). A few plaques are found in the cortex in a small number of subjects from the fourth decade on; a steep rise in incidence occurs in the seventh and eighth decade, and by the ninth decade, $75-80 \%$ of normal subjects have some plaques (Tomlinson, 1972), though in most subjects they are small in number, and often concentrated in the deep cortical layers. Usually the greatest number are found in the amygdaloid complex and hippocampal gyrus, and a much smaller number in the deep nuclear masses and hypothalamus. Occasionally, in a non-demented old person, plaque numbers reach similar proportions and overlap the levels of plaques found in the demented group (Tomlinson \& Henderson, 1976).

The situation concerning tangles is different. A few affected cells can be found in the hippocampal pyramidal layer in all patients above 50 years (Ball, 1976), the other most involved areas being the uncal cortex and the subiculum and, occasionally, the hippocampal gyrus. The number of cells affected in the hippocampus increases with age but does not reach the massive numbers found in Alzheimer's disease (Ball, 1976). Tangles in normal subjects are, however, absent or scarce in the neocortex (Tomlinson et al. 1968; Tomlinson, 1979; Matsuyama \& Nakamura, 1978), being found in this situation in large numbers only in demented cases.

The relationship between plaques and tangles is unknown. In normal old age there can be no direct anatomical connection between the localized tangles in the hippocampus and the widely scattered plaques which are commonly found in the neocortex. In Alzheimer's disease, when tangles and plaques are intermingled in great numbers in the neocortex together, it is tempting to postulate that the axons of tangle-bearing neurons terminate in the abnormal bulbous sproutings which constitute the bulk of the plaque, but there is no direct evidence for this and it is even possible that the nerve terminals forming the plaque only arise in neurons unaffected by tangle formation. Furthermore, the occurrence of some older demented subjects with numerous neocortical plaques 
and very few neocortical tangles and, more rarely, with numerous tangles and few plaques suggests that these two phenomena, though frequently occurring together in Alzheimer's disease, are not closely related structurally and may arise independently. The occurrence of tangles in the absence of plaques in post-traumatic dementia, in the Parkinsonism-dementia syndrome, and in postencephalitic Parkinsonism illustrates their independent occurrence in other conditions.

Though forming the chief morphological markers of Alzheimer's disease, the role played by plaques and tangles in the symptomatology of Alzheimer's disease is also unknown. The grossly abnormal neurites of plaques, intermingled or clustered around a mass of amyloid, would seem most unlikely to perform a normal function so far as conduction and transmission of nervous impulses are concerned, despite possessing apparently normal synapses. The presence of the latter sustains the hope that the synapses of the plaque might be susceptible to pharmacological influence and that, if the process of plaque formation can be reversed (and the amyloid reabsorbed), something approaching normal structure might result. Neurofibrillary tangles constitute abnormal fibrillary proteins, but whether they have an abnormal function in themselves, are physiologically inactive, or reduce function by interfering with the flow of material from cell soma to axons, dendrites and terminals, is not known. Nevertheless, several studies, starting with that of Corsellis (1962), have shown the association of dementia with the presence of large numbers of neocortical plaques and tangles by comparison with non-demented subjects, the conclusion being drawn (Roth et al. 1966; Blessed et al. 1968; Tomlinson et al. 1970; Constantinidis, 1978; Constantinidis et al. 1978) that it is the quantity and distribution of these structures, not their mere presence, which distinguishes Alzheimer's disease from non-demented patients. Blessed et al. (1968) showed a tendency for plaque formation to be greater in the more severely demented subjects and found (Tomlinson et al. 1970) that all patients with many neocortical tangles were demented. Tomlinson et al. (1970) also found greater quantities of tangles in the anterior temporal lobes in the majority of cases of Alzheimer's disease; Ball (1976) quantified the greater numbers of tangles by detailed, serial section analysis. Constantinidis (1978) found that numerous neocortical tangles were associated with aphasia, apraxia and agnosia in $91 \%$ of cases, whereas these instrumental disorders only occur in $32 \%$ of cases when neurofibrillary tangles are limited to the hippocampus and neighbouring temporal cortex, and in only $16 \%$ of cases if tangles are present only in small numbers in the hippocampus. When senile plaques are present alone only $12 \%$ of demented cases show instrumental signs. Blessed (personal communication), in a recent study of pathological and clinical data from the Newcastle study, found that parietal lobe symptomatology (aphasia-apraxia-agnosia) is closely related to the presence of numerous neocortical tangles in old demented subjects, but that demented old subjects with only large numbers of senile plaques were largely free of such symptomatology. In pre-senile Alzheimer's disease numerous neocortical tangles are invariable, and marked parietal lobe signs are usually a prominent feature of the disease.' In the senile group with parietal lobe signs many neocortical plaques and tangles are usually present; with parietal lobe signs absent, neocortical tangles are usually few or absent. If these findings (and those of Constantinidis, 1978) are confirmed, there may be considerable merit in agreeing on a clinical and pathological nomenclature to distinguish these two sub-varieties of dementing syndromes in old age.

The growing evidence of abnormalities in various components of the cholinergic transmitter system in Alzheimer's disease (Davis \& Maloney, 1976; Perry et al. 1977; Spillane et al. 1977; White et al. 1977) may also be partly related to or reflected by plaque formation. Thus a significant decline in cholineacetyl-transferase occurs with increasing plaque numbers in the neocortex of non-demented and demented old people (Perry et al. 1978); Perry \& Perry (1980) also showed significant correlations between plaque numbers and decreasing acetylcholinesterase. The diminution of these enzymes is in contrast to the normal levels of the muscarinic acetylcholine receptor (Perry et al. 1977; Davies \& Verth, 1978), the latter finding again fitting with the apparent ultrastructural integrity of the synapse, despite the presence of grossly abnormal pre-synaptic terminals.

Thus considerable indirect evidence exists that plaques and tangles of Alzheimer's disease may have relevance to some features of the actual dementing process. A considerable body of evidence (De Fendis, 1974; Karczmar, 1975) links the cerebral cholinergic system with many behavioural 
patterns (sleep, arousal, sensory, emotion and learning activities) which are frequently severely disturbed in Alzheimer's disease. So far, however, the evidence is no more than indirect, and therapeutic attempts to correct the cholinergic defect have been without significant or lasting benefit (Loew, 1980), though slight improvement has been claimed in some mild and moderate cases of presumed Alzheimer's disease treated with choline and lecithin (Christie et al. 1979; Etienne et al. 1979); it is clearly essential to explore all reasonable avenues of rectifying the levels of the proven decreased components of the cholinergic system by the use of rigorously controlled trials.

Whereas no evidence on the functional effects of plaques in experimental animals exists, evidence relating to disturbed behaviour and neuronal function in animals with neurofibrillary degeneration induced by the intracranial application of aluminium salts has accumulated (Crapper, 1976). The tangles so produced are not helically twisted paired filaments, but $10 \mathrm{~nm}$ straight filaments (Terry \& Pena, 1965). Animals so treated have a 7-10 day asymptomatic period, although neurofibrillary degeneration is present by the fourth day and is extensive by the ninth (Crapper \& Dalton, 1973a, b). Previously normal cats, however, showed some motor incoordination, impairment of short-term memory and deterioration of an acquired avoidance response within 7-10 days of the aluminium injection; motivational mechanisms, EEG and visual evoked potentials were not affected until a late stage of the neurological illness. Even in the late stages of the encephalopathy, when neurofibrillary tangles were present in almost all spinal cord motor neurons, axon conduction velocity is unaffected in the sciatic nerve, as is the electromyogram and muscle and peripheral nerve histology (Crapper, 1973). Motor neuron resting potential and antidromic spikes recorded on individual neurons showing neurofibrillary tangles did not differ from normal (Crapper, 1973). Furthermore, axonal transport in similarly affected rabbits is normal (Liwnicz et al. 1974). Single neuron sampling (Crapper \& Tomko, 1975; Tomko \& Crapper, 1974) within the visual cortex of aluminium treated animals showed a reduction in spontaneous discharge rate probably related to a failure of postsynaptic potentials, this failure probably being restricted to cells with neurofibrillary degeneration.

Is plaque or tangle formation related to the cortical neuron loss thought by many to be severe in Alzheimer's disease, and how good is the evidence for such neuron loss? In the pre-senile form, the brain is almost invariably severely atrophied, and its weight is often around or below $1000 \mathrm{~g}$. Total cortical and white matter volume is also reduced (Corsellis, 1976 b; Hubbard \& Anderson, 1981 ), so that the absolute volume of neuron-bearing cortex is diminished. Since plaques in many instances occupy a considerable volume of the cortex, cortical atrophy would be more severe without them and the volume of neuron-bearing cortex still further reduced. Counts of neurons per unit area or volume of cortex from histological preparations have been few and have yielded varying results, though the majority of reports have favoured some degree of neuron loss (Colon, 1972; Shefer, 1973; Terry et al. 1980; Brun \& Gustafson, 1976) with some areas slightly, but others heavily, affected. Neuron loss is undoubtedly severe in the anterior temporal lobes of many subjects but cell loss in many cortical areas, particularly in the senile cases (Tomlinson \& Henderson, 1976; Terry et al. 1980), may have been over-estimated in the past. However, taking cortical volume loss into account and the neuron loss per unit volume found by most observers using quantitative sampling techniques, the average case of pre-senile Alzheimer's disease seems likely to have lost some $30-40 \%$ more neurons than has the normal subject by that age. Considering the almost uniform agreement from quantitative studies, that cortical neurons are lost throughout life in normal subjects (Brody, 1955, 1970; Tomlinson \& Henderson, 1976; Colon, 1972; Shefer, 1973), the additional loss sustained in pre-senile Alzheimer's disease is likely to result in a brain which has lost in excess of $60 \%$ of its original cortical nerve cells. Cortical neuron loss in young and middle-aged adults cannot, however, be due to plaque and tangle formation, since both occur rarely during that period. Further, plaque formation cannot, initially at least, produce cell loss, since the abnormal neurites of the plaques clearly need functioning neurons to support them. Indeed, since the terminals are grossly enlarged (hypertrophied rather than atrophied), the parent neurons may be sustaining a higher metabolic demand than normal. Also, Terry et al. (1980) failed to find any correlation between plaque counts and neuron numbers in the cortex in SDAT. No good evidence therefore exists to associate plaque formation directly with neuron loss, unless the neurites of a plaque represent attempted regeneration 
or sprouting of axons as a response to diminishing numbers of nerve processes resulting from neuron and dendritic loss initiated by some other means. Such a hypothesis ignores the presence of amyloid within plaques, something which appears fundamental to our understanding of plaque genesis.

Unfortunately, we do not know the cells of origin of the neurites within a plaque or whether the clusters of neurites forming a plaque arise from many, few, or even a single neuron, though the latter seems unlikely. In the absence of such knowledge, there is no way in which the neurons whose terminals end in plaques can be studied, and we remain ignorant of the morphology, neurochemistry and physiological behaviour of the neurons involved in plaque formation.

There is, equally, no certain relationship between tangle formation and neuron loss or tangle formation and the dendritic abnormalities demonstrated in normal ageing and demented subjects (Scheibel et al. 1975; Scheibel, 1978). Dendritic and bouton loss in some cortical pyramidal cells is quantitatively greater in Alzheimer's disease than in age-matched controls (Mehraein et al. 1975), but it is not established that the neurons with tangles are also those with grossly abnormal dendritic trees. It is highly unlikely that the cells with grossly abnormal dendritic processes demonstrated in normal old age are the site of tangle formation, since within the neocortex in normal old age neurofibrillary tangles are scarce and often not demonstrable at all. Similarly, it is not known whether tangle formation contributes to neuronal death and loss, though it is certain that it has nothing to do with neuron loss in normal subjects in the cortex and a number of other sites (Brody, 1955, 1976; Colon, 1972; Tomlinson \& Henderson, 1976; Corsellis, 1976 b; Tomlinson \& Irving, 1977; Henderson et al. 1980), including the locus coeruleus (Brody, 1976; Tomlinson et al. 1981).

The pathogenesis and life history of human plaques and tangles are also unknown. Electron microscopic evidence suggests that the earliest evidence of plaque formation is a small cluster of abnormal terminals which, as they continue to grow in number, become associated with increasing amounts of amyloid to form what has been described as the mature plaque (Terry \& Wisniewski, 1970). Acceptance of this view has implications for the role of amyloid in plaque formation, since some observers in the past have seen amyloid deposition as the primary lesion which stimulates plaque formation (Schwartz, 1970). If the amyloid of plaques results from an antigen-antibody response in the cerebral tissues with subsequent damage to neighbouring axons, then we have a logical beginning from which the development of plaques can be studied (Terry \& Wisniewski, 1970). The nature of the amyloid of plaques is not yet established. Ishii \& Haga (1976) obtained positive reactions to immunoglobulins in amyloid fibrils in plaques. However, evidence that different mechanisms may be involved in the deposition of amyloid in cerebral vessels and plaques in demented subjects has been presented by Torack \& Lynch (1981), who demonstrated immunoglobulins in the amyloid of three cases of congophilic angiopathy but considered an endogenous substrate more likely in the amyloid of plaques. Powers \& Spicer (1977) and Powers \& Skeen (1980) have indeed demonstrated similarities between plaque and apud amyloid. Johnson et al. (1981) have produced evidence that plaque and vessel amyloid may share a common antigen with neurofibrillary tangles. It cannot be assumed at this time that the amyloid content of plaques in normal and demented old subjects have the same chemical constituents or origins, or that all the plaque amyloid occurring in different cases in Alzheimer's disease is identical. It is not certain that plaque amyloid has the same origins or chemical constitution as vascular amyloid (Torack \& Lynch, 1981) and the latter is common, though not constant, in Alzheimer's disease and normal old age ('Wright $e t$ al. 1969; Morimatsu et al. 1975). Vascular amyloid is present in many subjects with Alzheimer's disease, but may be absent even when plaques are extremely numerous (Mandybur, 1975; Mountjoy et al. 1982), and there is certainly no constant relationship between the two. Thus plaque amyloid may be heterogeneous in origin and chemical constitution, as seems likely with the two types of amyloid already identified in the senile heart (Cornwell \& Westermark, 1980). To establish whether or not this is so is of fundamental importance since, whatever the connection between plaque amyloid and the surrounding neurites, the close association cannot be coincidental. The possibly heterogeneous nature of amyloid in plaques and vessels has to be considered in any investigation into cerebral amyloid, as does the difficulty in extraction procedures, of establishing what proportion comes from vessel walls or from plaques. Certain forms of amyloid are known to be secreted with 
tumours, such as the medullary thyroid carcinoma (Glenner et al. 1973). The possibility therefore arises that plaque amyloid may result from neurosecretion or from the modification of neuropeptides. Our lack of knowledge of the morphological characteristics of neuropeptides means that we cannot exclude them as precursors of plaque amyloid or even as constituents of neurofibrillary tangles. Indeed, the neuropeptide, substance $P$, has been shown to form polyuric fibrillary aggregates with ultrastructural dimensions in the same range as has been reported for amyloid fibrils (Perry $e t$ al. 1981). The origin of the paired helical filaments of the human tangle is also uncertain, with evidence supporting a possible derivation from human neurotubules (Iqbal et al. 1974, 1975, 1978; Schlaepfer, 1978; Grundke-Iqbal et al. 1979) and neurofilaments (Gambetti et al. 1980, 1981) being reported. Perhaps through different mechanisms or under different circumstances, PHF may derive from either or both of these components of the normal neuron.

Once the plaque and the tangle have formed within the human brain, do they ever disappear? Here, again, we have no certain knowledge. An increase in the incidence of plaques within normal subjects throughout life and the involvement of increasing numbers of tangles in the anterior temporal lobes do not demonstrate their indestructability. The vast numbers of plaques and tangles in Alzheimer's disease establish that the majority of such people die without reabsorption or disintegration of many plaques and tangles. However, in the anterior temporal lobes and some other areas of the brain (Brun \& Gustafson, 1976) there is suggestive evidence that the end result of massive tangle and plaque formation, and whatever other destructive processes occur in Alzheimer's disease, may lead to the final disintegration of cortical tissue. This occurs in only restricted cerebral sites and is not a striking feature in the majority of cases. One would have to conclude therefore that plaques and tangles probably have an extremely long life-cycle and that, once formed, they are probably present for many years, but they are not necessarily permanent or irremovable.

The view has frequently been advanced that Alzheimer's disease represents an exaggeration or acceleration of the normal ageing process. A threshold limit of plaque formation has been conceived below which the majority of old subjects are well-preserved intellectually and above which the majority show evidence of dementia. This might be true without supporting the view that Alzheimer's disease represents an acceleration of normal ageing. Such a proposition is not supported by some of the other morphological features of the disease and is far too restrictive of thought about the origin of Alzheimer's disease to be allowed as a dominant hypothesis. The study of neocortical tangle formation lends no support to the proposition since there is no continuum in appearances within the cortex of non-demented subjects and cases of Alzheimer's disease. In non-demented old subjects tangles are rare in the neocortex, whereas in Alzheimer's disease they are often present in vast numbers and are an inevitable marker of dementia. Some factor which is absent in normal old age therefore stimulates neocortical tangle formation. It is very unlikely that with increasing longevity we are all destined to develop Alzheimer's disease. In extreme old age sufficient neurons may be lost and dendritic abnormalities occur for dementia to develop on that basis alone, but present evidence is against the possibility that Alzheimer's disease would acount for an ever increasing proportion of cases. Erlich \& Davis (1980) found a diminution in the incidence of dementia above the age of 90 years; they found no evidence for an inevitable accumulation of plaques and tangles with increasing age. Unfortunately, their histological observations were made on hippocampe 1 sections only, an inadequate procedure in research and morphological diagnosis in Alzheimer's disease. Indeed, in the ninth and tenth decades dementia, although usually of the Alzheimer type morphologically, presents an increasing number of cases with plaque formation only (Terry, personal communication), and a small, but increasing, number which have no obvious morphological basis. Beyond the tenth decade dementia may result from other factors of which we have no knowledge. Some subjects may be genetically resistant to tangle and plaque formation and therefore to Alzheimer's disease, and it is possible that the susceptible population to this disorder is largely wiped out by the tenth decade.

So far no animal has been found which naturally, or under experimental conditions, develops both tangles and plaques. A few plaques, similar on light microscopy to the human variety, have been found in ageing dogs (Brunmuhl, 1956; Pauli \& Luginbühl, 1971) and Wisniewski et al. (1970b) 
confirmed their ultrastructural similarity to the human (primitive) plaque, though they failed to find abnormal fibrils in the neurites. Wisniewski et al. (1973) found similar plaques in ageing rhesus monkeys, including PHF, though neurons showing tangles were not identified. Indeed, tangles consisting of PHF do not appear to have been identified in any animal as a spontaneously occurring phenomenon.

Experimentally induced tangles, mostly by methods unlikely to have direct relevance to the tangles of Alzheimer's disease, are only similar to the human variety on light microscopy, consisting of straight filaments. This applies to tangles induced by the intracerebral inoculation of aluminium phosphate (Klatzo et al. 1965; Terry \& Pena, 1965), by cochicine (Wisniewski \& Terry, 1967) and mitotic spindle inhibitors (Schochet et al. 1968; Wisniewski et al. 1968), the latter substances being tubulin binding agents, as are a number of other substances capable of producing tangles experimentally (Ghetti, 1980). Interest in aluminium as a possible aetiological agent was heightened by the report of raised brain aluminium levels in patients with Alzheimer's disease (Crapper $e t$ al. 1976) and by the experimental production of tangles by systemic aluminium (De Boni et al. 1976). McDermott et al. (1977), however, failed to confirm increased aluminium concentrations in Alzheimer brains; furthermore, patients with dialysis encephalopathy associated with much higher levels of brain aluminium (McDermott et al. 1978) show neither tangles nor plaques (Burkes et al. 1976), a fact confirmed in our laboratory. Contradictory evidence has also arisen from studies of tangle-bearing neurons in Alzheimer's disease. Using X-ray spectrometry, Peri \& Brody (1980) found foci of aluminium within the nuclei of tangle-bearing neurons, whereas Duckett \& Galle (1980) were unable to provide an indication of aluminium in the pathogenesis of tangles by electron-microprobe studies. Unlikely as any aetiological role would appear, the aluminium concentration in normal and Alzheimer brains needs further investigation.

Tangles in post-encephalitic Parkinsonism and in subacute sclerosing pan-encephalitis demonstrate their formation following virus infections in humans. One animal model in which neuritic plaques can be predictably produced is now available since Bruce \& Fraser (1975) and Bruce et al. (1976) showed plaque formation in certain strains of mice infected with particular strains of scrapie agent. Some of these plaques are ultrastructurally similar to the human variety (Wisniewski et al. 1975), though lacking PHFs. The effects of the genetic constitution of mice on the inoculation period of scrapie (Dickinson et al. 1968, 1969) have been elucidated to the extent of the identification of two alleles responsible for the shortening or prolongation of the incubation period after injection with a particular scrapie agent, and identification of scrapie agent properties responsible for plaque formation now appears likely. The relevance of these observations to any disease of man is purely speculative, but the presence of transmissible agents with prolonged incubation period in man (Kuru and Creutzfeldt-Jakob disease) and with other similarities to scrapie (with abundant plaques in two-thirds of the cases of Kuru and $10 \%$ of cases of Creutzfeldt-Jakob disease) must stimulate investigation of the possibility that Alzheimer's disease, with its late onset (and therefore perhaps after long incubation), might be similarly determined by genetic and 'infective' agent factors. Major variations exist in the incubation period, clinical manifestations and pathological changes in different animals infected with material from Creutzfeldt-Jakob disease and Kuru (Gibbs et al. 1979), and many strains of agent responsible for these diseases apparently exist. Traub et al. (1977) report a number of cases of transmissible virus dementia or non-transmissible Creutzfeldt-Jakob disease in which plaques and tangles occurred at an age when their presence was not likely to be due to ageing. Their separation of the spongiform encephalopathies of man into transmissible spongiform encephalopathies and non-transmissible Creutzfeldt-Jakob disease may prove to be unnecessary if the disorders are due to different strains of an agent producing different results in inoculated animals (including extremely long incubation periods), as occurs in scrapie infected mice. Attempts to transmit Alzheimer's disease to experimental animals have failed, except from two cases of familial Alzheimer's disease (Gibbs et al. 1979), and there is no direct evidence for infectivity of slow agent type in Alzheimer's disease and no firm evidence of transmission of Creutzfeldt-Jakob disease from one human to another except by direct inoculation. Nevertheless, the possibility from the variations in histology in Creutzfeldt-Jakob disease, with neuritic plaques produced in a small number of cases, 
clearly tempts the speculation that transmissible agents, producing a wide spectrum of human disorder, may exist.

Recently, De Boni \& Crapper (1978) and Crapper-McLachlan \& De Boni (1980) have reported the successful stimulation of paired helical filaments, not absolutely identical to the human variety, in the processes of a small proportion of human foetal neurons in culture exposed to high dilutions of a cell-free saline extract of cerebral cortex taken from cases of Alzheimer's disease. The agent has also been detected by a similar technique in the CSF in three cases of clinically diagnosed Alzheimer's disease and in one control (Crapper-McLachlan \& De Boni, 1980), the latter raising the possibility that PHF 'agent' may occur in normal brain. Clearly, the continued search for an infective agent and a susceptible host is justified at this time.

Whatever the significance ultimately assigned to plaques and tangles in the symptomatology, pathology, neurochemistry, pathogenesis and aetiology of Alzheimer's disease, continued investigation of these two changes remains a major challenge in all research into dementia and ageing in the human central nervous system. Until their role is precisely defined, knowledge of an important area of neuropathology and human ageing will be incomplete.

B. E. TOMLINSON

\section{REFERENCES}

Ball, M. J. (1976). Neurofibrillary tangles and the pathogenesis of dementia; a quantitative study. Neuropathology and Applied Neurobiology 2, 395-410.

Blessed, G., Tomlinson, B. E. \& Roth, M. (1968). The association between quantitative measures of dementia and of senile change in the cerebral grey matter of elderly subjects. British Journal of Psychiatry 114, 797-811.

Brody, H. (1955). Organisation of the cerebral cortex. III: A study of ageing in the human cerebral cortex. Journal of Comparative Neurology 102, 511-556.

Brody, H. (1970). Structural changes in ageing nervous system. Interdisciplinary Topics in Gerontology 7, 9-21.

Brody, H. (1976). An examination of cerebral cortex and brain stem ageing. In Neurobiology of Ageing, vol. 3. (ed. R. D. Terry and S. Gershon), pp. 177-181. Raven Press: New York.

Bruce, M. E. \& Fraser, A. H. (1975). Amyloid plaques in the brains of mice infected with scrapie: morphological variations and staining properties. Neuropathology and Applied Neurobiology 1, 189-202.

Bruce, M. E., Dickinson, A. G. \& Fraser, H. (1976). Cerebral amyloidosis in scrapie in the mouse: effect of agent strain and mouse genotype. Neuropathology and Applied Neurobiology 2, $471-478$.

Brun, A. \& Gustafson, L. (1976). Distribution of cerebral degeneration in Alzheimer's disease. A clinico-pathological study. Archiv für Psyhiatrie und Nervenkrankheiten 223, 15-133.

Brunmuhl, A. (1956). Kongophile Angiopathie und senile Plaques bei greisen Hunden. Archiv für Psychiatrie und Nervenkrankhieten 194, 396-414.

Burger, P.C. \& Vogel, F.S. (1973). The development of the pathological changes of Alzheimer's disease and senile dementia in patients with Down's syndrome. American Journal of Pathology 73, 457-476.

Burkes, J. S., Huddlestone, J., Alfrey, A. C., Norenberg, M. D. S. \& Lewin, E. (1976). A fatal encephalopathy in chronic haemodialysis patients. Lancet i, 764-768.

Christie, J. E., Glen, A. I. M., Yates, C. M., Blackburn, I. M., Shering, A., JeHinek, E. H. \& Zeisel, S. (1969). Choline and lecithin effects on CSF choline levels and on cognitive function in Alzheimer pre-senile dementia. In Alzheimer's Disease. Early Recognition of Potentially Reversible Deficits (ed. A. I. M. Glen and L. J. Whalley), pp. 163-168. Churchill Livingstone: Fdinburgh.

Colon, E. J. (1972). The elderly brain. A quantitative analysis of the cerebral cortex in two cases. Psychiatrie, Neurologie Neurochirurgie (Amsterdam) 75, 261-270.
Constantinidis, J. (1978). Is Alzheimer's disease a major form of senile dementia? Clinical, anatomical and genetic data. In Alzheimer's Disease, Senile Dementia and Related Disorder (Ageing, vol. 7) (ed. R. Katzman, R. D. Terry and K. L. Bick), pp. 15-25. Raven Press: New York.

Constatinidis, J., Richard, J. \& de Ajuriaguerra, J. (1978) Dementia with senile plaques and neurofibrillary tangles. In Studies in Geriatric Psychiatry (ed. A. D. Isaacs and F. Post), pp. 119-152. Wiley: New York.

Cornwell, G. G. \& Westermark, P. (1980). Senile amyloidosis: a protean manifestation of the ageing process. Journal of Clinical Pathology 33, 1146-1152.

Corsellis, J. A. N. (1962). Mental Illness and the Ageing Brain. Oxford University Press: London.

Corsellis, J. A. N. (1976a) Ageing and the dementias. In Greenfield's Neuropathology (3rd edn) (ed. W. Blackwood and J. A. N. Corsellis), pp. 796-848. Edward Arnold: London.

Corsellis, J. A. N. (1976b). Some observations on the Purkinje cell population and on brain volume in human ageing. In Neurobiology of Ageing, vol. 3. (ed. R. D. Terry and S. Gershon), pp. 205-209. Raven Press: New York.

Corsellis, J. A. N., Bruton, C. J. \& Freeman-Browne, D. (1973). The aftermath of boxing. Psychological Medicine 3, 270-303.

Crapper, D. R. (1973). Experimental neurofibrillary degeneration and altered electrical activity. Electroencephalography and Clinical Neurophysiology 35, 575-588.

Crapper, D. R. (1976). Functional consequences of neurofibrillary degeneration. In Neurobiology of Ageing, vol. 3. (ed. R. D. Terry and S. Gershon), pp. 405-432. Raven Press: New York.

Crapper, D. R. \& Dalton, A. J. (1973a). Aluminium induced neurofibrillary degeneration, brain electrical activity and alterations in acquisition and retention. Physiology and Behaviour 10, 935945.

Crapper, D. R. \& Dalton, A. J. (1973b). Alterations in short term retention, conditioned avoidance response acquisition and motivation following aluminium induced neurofibrillary degeneration. Physiology and Behaviour 10, 925-933.

Crapper, D. R. \& Tomko, G. J. (1975). Neuronal correlates of an encephalopathyind uced by aluminium neurofibrillary degeneration. Brain Research 97, 253-264.

Crapper, D. R., Krishnan, S. S. \& Quittkat, S. (1976). Aluminium, neurofibrillary degeneration and Alzheimer's disease. Brain 99, 67-80.

Crapper-McLachlan, D. R. \& De Boni, U. (1980). Aetiologic factors in senile dementia of Alzheimer type. In Ageing of the Brain and 
Dementia (Aging, vol. 13) (ed. L. Amaducci, A. N. Davison and P. Antuono), pp. 173-181, Raven Press: New York.

Davies, P. \& Maloney, A. F. (1976). Selective loss of cholinergic neurons in Alzheimer's disease. Lancet ii, 1403.

Davies, P. \& Verth, A. H. (1978). Regional distribution of muscarinic acetylcholine receptor in normal and Alzheimer-type dementia brains. Brain Research 138, 385-392.

Dayan, A. D. \& Ball, M. J. (1973). Histometric observations on the metabolism of tangle-bearing neurons. Journal of Neurological Science 19, 422-426.

De Boni, U. \& Crapper, R. D. (1978). Paired helical filaments of the Alzheimer type in cultured neurons. Nature 271, 566-568.

De Boni, U., Otoos, S., Scott, J. W. \& Crapper, D. R. (1976). Neurofibrillary degeneration induced by systemic aluminium. Acta Neuropathologica (Berlin) 35, 285-294.

De Fendis, F. V. (1974). Central Cholinergic Systems and Behaviour. Academic Press: New York.

Dickinson, A. G., Meikel, V. M. \& Fraser, H. (1968). Identification of a gene which controls the incubation period of some strains of scrapic in mice. Journal of Comparative Pathology 78, 293-299.

Dickinson, A. G., Meikel, V. M. \& Fraser, H. (1969). Genetic control of the concentration of ME7 scrapie agent in the brain of mice. Journal of Comparative Pathology 79, 15-22.

Duckett, S. \& Galle, P. (1980). Electron-microprobe studies of aluminium in the brains of cases of Alzheimer's disease and ageing patients. Journal of Neuropathology and Experimental Neurology 39, 350 .

Erlich, S. S. \& Davis, R. L. (1980). Alzheimer's disease in the very aged. Journal of Neuropathology and Experimental Neurology 39 , 352.

Etienne, P., Gauthier, S., Dastoor, D., Collier, B. \& Ratner, J. (1979) Alzheimer's disease: clinical effect of lecithin treatment. In Alzheimer's Disease. Early Recognition of Potentially Reversible Deficits (ed. A. I. M. Glen and L. J. Whalley), pp. 173-178. Churchill Livingstone: Edinburgh.

Gambetti, P., Velasco, M. E., Dahl, D., Bignami, A., Roessmann, U. \& Sindely, S. D. (1980). Alzheimer's neurofibrillary tangles: an immunohistochemical study. In Aging of the Brain and Dementia (Aging, vol. 13) (ed. L. Amaducci, A. N. Davison and P. Antuono), pp. 55-63. Raven Press: New York.

Gambetti, P., Autilio-Gambetti, L. \& Shecket, G. (1981). Immunological and silver staining characteristics of neurofibrillary tangles of Alzheimer type (NFT-AT). Journal of Neuropathology and Experimental Neurology 30, 317.

Ghetti, B. (1980). Experimental studies on neurofibrillary degeneration. In Ageing of the Brain and Dementia (Aging, vol. 13) (cd. L. Amaducci, A. N. Davison and P. Antuono), pp. 183-198. Raven Press: New York.

Gibbs, C. J., Gadjusek, D. C. \& Amyer, H. (1979). Strain variations in the viruses of Creutzfeldt-Jakob disease and Kuru. In Slow Transmissible Diseases of the Nervous System, vol. 2. (ed. S. B. Prusiner and W. J. Hadlow), pp. 87-110. Academic Press: New York.

Gibson, P. H., Stones, M. \& Tomlinson, B. E. (1976). Senile changes in the human neocortex and hippocampus compared by the use of the electron and light microscopes. Journal of Neurological Science 27, 389-405.

Glenner, G. G., Terry, W. \& Isersky, C. (1973). Amyloidosis: its nature and pathogenesis. Seminal Haematology 10, 65-86.

Gonatas, N. K. \& Gambetti, P. (1970). The pathology of the synapse in Alzheimer's disease. In Ciba Foundation Synposium on Alzheimer's Disease and Related Conditions (ed. G. E.W. Wolstenholme and M. O'Connor), pp. 169-183. Churchill Livingstone: London.

Gonatas, N. K., Anderson, W. \& Evangelista, I. (1967). The contribution of altered synapses in the senile plaque: an electronmicroscopic study in Alzheimer's dementia. Journal of Neuropathology and Experimental Neurology 26, 25-39.

Grundke-Iqbal, I., Johnson, A. B., Terry, R. D., Wisniewski, H. M. \& Iqbal, K. (1979). Alzheimer neurofibrillary tangles: antiserum and immunohistological staining. Annals of Neurology 6, 532-539.
Henderson, G., Tomlinson, B. E. \& Gibson, P. H. (1980). Cell counts in human cerebral cortex in normal adults throughout life using an image analysing computer. Journal of Neurological Science 46. 113-136.

Hirano, A. (1974). Parkinsonism-dementia complex on Guam: current status of the problem. In Proceedings of the 10th International Congress of Neurology, Barcelona 1973 (ed. A. Subirana and J.M. Espadaler), p. 348. Excerpta Medica: Amsterdam.

Hirano, A., Malamud, N. \& Kurland, L. T. (1961). Parkinsonismdementia complex, an endemic disease on the Island of Guam. II: Pathological features. Brain 84, 662-679.

Hubbard, B. M. \& Anderson, J. M. (1981). A quantitative study of cerebral atrophy in old age and senile dementia. Journal of Neurological Science 50, 135-145.

Iqbal, K., Wisniewski, H. M., Shelanski, M. L., Brostoff, S., Liwnicz, B. H. \& Terry, R. D. (1974). Protein changes in senile dementia. Brain Research 77, 337-343.

Iqbal, K., Wisniewski, H. M., Grundke-Iqbal, I., Koothals, J. K. \& Terry, R. D. (1975). Chemical pathology of neurofibrils: neurofibrillary tangles of Alzheimer's pre-senile dementia. Journal of Histochemistry and Cytochemistry 23, 563-569.

Iqbal, K., Grundke-Iqbal, I., Wisniewski, H. M. \& Terry, R. D. (1978). Chemical relationship of the paired helical filaments of Alzheimer's dementia to human normal neurofilaments and neurotubules. Brain Research 142, 321-332.

Ishii, T. (1976). On various ultrastructural types of distended processes and degenerated synapses in senile brain, particularly those in senile plaques. Advances in Neurological Science 20, 373-384.

Ishii, T. \& Haga, S. (1976). Immunoelectronmicroscopic localisation of immunoglobulins in amyloid fibrils of senile plaques. Acta Neuropathologica (Berlin) 36, 243-249.

Jervis, G. A. (1948). Early senile dementia in mongoloid idiocy. American Journal of Psychiatry 105, 102-106.

Johnson, A. B., Cohen, S. A., Said, S. I. \& Terry, R. D. (1981). Neuritic plaque amyloid, microangiopathy and Alzheimer neurofibrillary tangles: do they share a common antigen? Journal of Neuropathology and Experimental Neurology 40, 310.

Karczmar, A. G. (1975). Cholinergic influences on behaviour. In Cholinergic Mechanisms (ed. P. G. Waser), pp. 501-529. Raven Press: New York.

Kidd, M. (1963). Paired helical filaments in electronmicroscopy in Alzheimer's disease. Nature (London) 197, 192-193.

Kidd, M. (1964). Alzheimer's disease - an electron microscopic study. Brain 87, 307-321.

Klatzo, 1., Wisniewski, H. \& Streicher, E. (1965). Experimental production of neurofibrillary degeneration. 1. Light microscopic observations. Journal of Neuropathology and Experimental Neurology 24, 187-199.

Krigman, M. R., Feldman, R. G. \& Bensch, K. (1965). Alzheimer's presenile dementia. A histochemical and electronmicroscopic study. Laboratory Investigation 14, 381-396.

Liwnicz, B. H., Kristensson, K., Wisniewski, H. M., Shelanski, M. L. \& Terry, R. D. (1974). Observations on axoplasmic transport in rabbits with aluminium induced neurofibrillary tangles. Brain Research 80, 413-420.

Loew, D. M. (1980). Pharmacological approaches to the treatment of senile dementia. In Aging of the Brain and Dementia (Aging, vol, 13) (ed. L. Amaducci, A. N. Davison and P. Antuono), pp. 287-304. Raven Press: New York.

Malamud, N., Hirano, A. \& Kurland, L. T. (1961). Pathoanatomic changes in amyotrophic lateral sclerosis on Guam. Archives of Neurology (Chicago) 5, 401-415.

Mandybur, T. I. (1975). The incidence of cerebral amyloid angiopathy in Alzheimer's disease. Neurology (Minneapolis) 25, 120-126.

Mandybur, T. I., Nagpaul, A. S., Pappas, Z. \& Niklowitz, W. J. (1977). Alzheimer's neurofibrillary change in subacute sclerosing panencephalitis. Annals of Neurology 1, 103-107.

Matsuyama, H. \& Nakamura, S. (1978). Senile changes in the brain 
in the Japanese: incidence of Alzheimer's neurofibrillary change and senile plaques. In Alzheimer's Disease, Senile Dementia and Related Diseases (Aging, vol. 7) (ed. R. Katzman, R. D. Terry and K. L. Bick), pp. 287-297. Raven Press: New York.

McDermott, J. R., Smith, A. I., Iqbal, K. \& Wisniewski, H. M. (1977). Aluminium and Alzheimer's disease. Lancet ii, 710-711.

McDermott, J. R., Ward, M. K., Smith, A. I., Parkinson, I. S. \& Kerr, D. N. S. (1978). Brain aluminium concentrations in dialysis encephalopathy. Lancet i, 901-903.

Mehraein, P., Yamada, M. \& Tarnowska-Dzidusko, E. (1975). Quantitation studies on dendrites in Alzheimer's disease and senile dementia. In Physiology and Pathology of Dendrites (ed. G. W. Kreutzberg), pp. 453-458. Raven Press: New York.

Morimatsu, M., Hirai, S., Murimatsu, A. \& Yoshikawa, M. (1975). Senile degenerative brain lesions and dementia. Journal of the American Geriatric Society 23, 390-406.

Mountjoy, C. Q., Tomlinson, B. E. \& Gibson, P. H. (1982). Amyloid and senile plaques and cerebral blood vessels. A semi-quatitative investigation of a possible relationship. (To be published).

Olson, M. I. \& Shaw, C. (1969). Pre-senile dementia and Alzheimer's disease in mongolism. Brain 92, 147.

Oyanagi, S. (1979). Aging of the central nervous system and its fine structure. Neurofibrillary change and senile plaques. Seishin Iqatu 21, 834-846. (In Japanese - quoted by Yagashita et al. 1981.)

Paula-Barbosa, M. N., Brito, R., Silva, C. A., Farin, R. \& Cruz, C. (1979). Neurofibrillary changes in the cerebral cortex of a patient with S.S.P.E. Acta Neuropathologica 48, 157-160.

Pauli, B. \& Luginbühl, G. (1971). Fluorescenzmikrokopische Untersuchungen der crebralen Amyloidose bei alten Hunden und senilen Menschen. Acta neuropathologica (Berlin) 19, 121-128.

Peri, D. P. \& Brody, A. R. (1980). Alzheimer's disease: X-ray spectrometric evidence of aluminium accumulation in neurofibrillary tangle-bearing neurons. Science 208, 297-298.

Perry, E. K. \& Perry, R. H. (1980). The cholinergic system in Alzheimer's disease. In Biochemistry of Dementia (ed. P. J. Roberts), pp. 135-183. John Wiley \& Sons: Chichester.

Perry, E. K., Perry, R. H., Blessed, G. \& Tomlinson, B. E. (1977). Necropsy evidence of central cholinergic deficits in senile dementia. Lancet i, 189.

Perry, E. K., Tomlinson, B. E., Blessed, G., Bergmann, K. \& Perry, R. H. (1978). Correlation of cholinergic abnormalities with senile plaques and ventral test scores in senile dementia. British Medical Journal ii, 1457-1459.

Perry, E. K., Oakley, A. E., Candy, J. M. \& Perry, R. H. (1981) Properties and possible significance of substance $P$ and insulin fibrils. Neuroscience Letters 25, 321-325.

Powers, J. M. \& Spicer, S. S. (1977). Histochemical similarity of senile plaque amyloid to apudamyloid. Virchows Archiv für pathologische Anatomie und Physiologie und für klinische Medizin 376, 107-115.

Powers, J. M. \& Skeen, J. T. (1980). An immunoperoxidase study of senile plaques. Journal of Neuropathology and Experimental Neurology 39, 385 .

Roth, M., Tomlinson, B. E. \& Blessed, G. (1966). Correlation between scores for dementia and counts of 'senile plaques' in cerebral grey matter of elderly subjects. Nature (London) 209, 109.

Scheibel, A. B. (1978). Structural aspects of the ageing brain: spine systems and the dendritic arbor. In Alzheimer's Disease, Senile Dementia and Related Disorders (Aging, vol. 7) (ed. R. Katzman, R. D. Terry and K. L. Bick), pp. 353-373. Raven Press: New York.

Scheibel, M. E., Lindsay, R. D., Tomiyasu, U. \& Scheibel, A. B. (1975). Progessive dendritic changes in the ageing human cortex Journal of Neuropathology and Experimental Neurology 47, 392-403.

Schlaepfer, W. W. (1978). Deformation of isolated neurofilaments and the pathogenesis of neurofibrillary pathology. Journal of Neuropathology and Experimental Neurology 37, 244-254.

Schochet, S. S. Jr, Lampert, P. W. \& Earle, K. M. (1968). Neuronal changes induced by intrathecal vincristine sulfate. Journal of Neuropathology and Experimental Neurology 27, 645-658.

Schwartz, P. (1970). Amyloidosis: Cause and Manifestations of Senile Deterioration. C. C. Thomas: Springfield, Ill.
Shefer, V. G. (1973). Absolute number of neurons and thickness of the cerebral cortex during aging, senile vascular dementia and Pick's and Alzheimer's disease. Neuroscience and Behavioural Physiology 6, 319-324.

Shibayama, H. \& Kitoh, J. (1978). Electronmicroscopic structure of the Alzheimer's neruofibrillary changes in a case of atypical senile dementia. Acta Neuropathologica (Berlin) 41, 229-234.

Solitare, G. B. \& Lamarche, J. B. (1966). Alzheimer's disease and senile dementia as seen in mongoloids. American Journal of Mental Deficiency 70, 840-848.

Spillane, J. A., White, P., Goodhardt, M. J., Flack, R. H. A., Bowen, D. M. \& Davison, A. N. (1977). Selective vulnerability of neurons in organic dementia. Nature (London) 266, 558-559.

Terry, R. D. (1963). The fine structure of neurofibrillary tangles in Alzheimer's disease. Journal of Neuropathology and Experimental Neurology 22, 269-292.

Terry, R. D. \& Pena, C. (1965). Experimental production of neurofibrillary degeneration. 2. Electronmicroscopy, phosphatase histochemistry and electron probe analysis. Journal of Neuropathology and Experimental Neurology 24, 200-210.

Terry, R. D. \& Wisniewski, H. (1970). The ultrastructure of the neurofibrillary tangle and the senile plaque. In Ciba Foundation Symposium on Alzheimer's Disease and Related Conditions (ed. G. E. Wolstenholme and M. O'Connor), pp. 145-168. Churchill Livingstone: London.

Terry, R. D., Gonatas, N. K. \& Weiss, M. (1964). Ultrastructural studies in Alzheimer's presenile dementia. American Journal of Pathology 44, 269-297.

Terry, R. D., Peck, A., Deteresa, R., Schechter, R. \& Horoupian, D. S. (1980). Some morphometric aspects of the brain in senile dementia of the Alzheimer type. Journal of Neuropathology and Experimental Neurology 39, 314.

Tomko, G. J. \& Crapper, D. R. (1974). Neuronal variability: non-stationary responses to identical visual stimuli. Brain Research 79, 405-418.

Tomlinson, B. E. (1972). Morphological brain changes in nondemented old people. In Aging of the Central Nervous System (ed. H. M. Van Praag and A. F. Kalverboer), pp. 38-57. Bohn: Haartem.

Tomlison, B. E. (1977). The pathology of dementia. In Dementia (2nd edn) (ed. C. E. Wells), pp. 113-180. F. A. Davis: Philadelphia

Tomlinson, B. E. (1979). The ageing brain. In Recent Advances in Neuropathology (ed. W. T. Smith and J. B. Cavanagh), pp. 129-159. Churchill Livingstone: Edinburgh.

Tomlinson, B. E. \& Henderson, G. (1976). Some quantitative cerebral findings in normal and demented old people. In Neurobiology of Aging, vol. 3 (ed. R. D. Terry and S. Gershon), pp. 183-204. Raven Press: New York.

Tomlinson, B. E. \& Irving, D. (1977). The numbers of limb motor neurons in the human lumbosacral cord throughout life. Journal of Neurological Science 34, 213-219.

Tomlinson, B. E. \& Kitchener, D. (1972). Granulovacuolar degeneration of the hippocampal pyramidal cells. Journal of Pathology 106, 165-185.

Tomlinson, B. E., Blessed, G. \& Roth, M. (1968). Observations on the brains of non-demented old people. Journal of Neurological Science 7, 331-356.

Tomlinson, B. E., Blessed, G. \& Roth, M. (1970). Observations on the brains of demented old people. Journal of Neurological Science $11,205-242$.

Tomlinson, B. E., Irving, D. \& Blessed, G. (1981). Cell loss in the locus coeruleus in senile dementia of Alzheimer type. Journal of Neurological Science 49, 419-428.

Torack, R. M. \& Lynch, R. G. (1981). Cytochemistry of brain amyloid in adult dementia. Acta neuropathologica 53, 189-196.

Traub, R., Gajdusek, D. C. \& Gibbs, C. J. Jr (1977). Transmissible virus dementia: The relation of transmissible spongiform encephalopathy to Creutzfeldtz-Jakob disease. In Aging and Dementia (ed. W. L. Smith and M. Kinsbourne), pp. 91-152. Spectrum Publications: New York.

White, P., Hiley, C. R., Goodhardt, M. J., Carrasco, L. H., Keet, 
J. P., Williams, I. E. I. \& Bowen, D. M. (1977). Neocortical cholinergic neurons in elderly people. Lancet $\mathrm{i}, 668-670$.

Wisniewski, H. M. \& Terry, R. D. (1967). Experimental colchicine encephalopathy. 1. Introduction of neurofibrillary degeneration. Laboratory Investigation 17, 577-587.

Wisniewski, H. M., Shelanski, M. L. \& Terry, R. D. (1968). Effects of mitotic spindle inhibitors on neurotubules and neurofilaments in anterior horn cells. Journal of Cell Biology 38, 224-229.

Wisniewski, H. M., Terry, R. D.\& Hirano, A. (1970a). Neurofibrillary pathology. Journal of Neuropathology and Experimental Neurology 29, 163-176.

Wisniewski, H. M., Johnson, A. B., Raine, C. S., Kay, W. J. \& Terry, R. D. $(1970 b)$. Senile plaques and cerebral amyloidosis in aged dogs. A histochemical study. Laboratory Investigation 23, 287-296.

Wisniewski, H. M., Ghetti, B. \& Terry, R. D. (1973). Neuritic (senile) plaques and filamentous changes in aged rhesus monkeys. Journal of Neuropathology and Experimental Neurology 32, 566-584.

Wisniewski, H. M., Bruce, M. E. \& Fraser, H. (1975). Infectious aetiology of neuritic (senile) plaques in mice. Science 190, 1108-1110.
Wisniewski, H. M., Narang, H. K. \& Terry, R. D. (1976a). Neurofibrillary tangles of paired helical filaments. Journal of Neurological Science 27, 173-181.

Wisniewski, H. M., Narang, H. K., Corsellis, J. A. N. \& Terry, R. D. $(1976 b)$. Ultrastructural studies of the neuropil and neurofibrillary tangles in Alzheimer's disease and post-traumatic dementia. Journal of Neuropathology and Experimental Neurology 35, 367.

Woodard, J. S. (1962). Clinico-pathological significance of granulovacuolar degeneration in Alzheimer's disease. Journal of Neuropathology and Experimental Neurology 21, 85-91.

Woodard, J. S. (1966). Alzheimer's disease in late adult life. American Journal of Pathology 49, 1157-1169.

Wright, J. R., Calkins, E., Breen, W. T., Stolte, G. \& Schultz, R. T. (1969). Relationship of amyloid to aging. Review of the literature and a systematic study of 83 patients derived from a general hospital population. Medicine 48, 39-60.

Yagashita, S., Itah, Y., Wang, N. \& Amano, N. (1981). Reappraisal of the fine structure of Alzheimer's neurofibrillary tangles. Acta Neuropathologica (Berlin) 54, 239-246. 